\title{
24 TO VANQUISH THE SOCIAL MONSTER: The Struggle for Social Inclusion among Peers in the Field of Systems Development
}

\author{
Thomas Elisberg \\ The IT University of Copenhagen \\ Copenhagen, Denmark \\ Richard Baskerville \\ Georgia State University \\ Atlanta, GA U.S.A.
}

\begin{abstract}
The mechanisms of social inclusion and exclusion may operate among professionals within organizations and communities of practice. These mechanisms can be embedded into formal organizational structures, and exert powerful control over who the members of organizations and communities will deem to be acceptable and unacceptable within their society. Using capital theories as a theoretical lens, we analyze the texts of interviews with knowledge leaders in a software development organization. The analysis reveals how a threshold event operates to bring inclusion of newcomers to a collection of social communities. Until the threshold event, communities of newcomers are socially excluded. The existence of the threshold event, and the nature of the threshold event, is an unspoken and unacknowledged structure used in creating the social fabric of the organization or community. It is collectively, yet implicitly, decided when such an event occurs, and the social inclusion triggered without any explication otherwise.
\end{abstract}

\section{INTRODUCTION}

Social inclusion and exclusion is often regarded from the perspective of large geographic communities. But these same phenomena can operate at an organizational level and consequently affect the design of information systems in software developing organizations because professional stakeholders are excluded from influence in the development process.

Please use the following format when citing this chapter:

Elisberg, T., and Baskerville, R., 2006, in IFIP International Federation for Information Processing, Volume 208, Social Inclusion: Societal and Organizational Implications for Information Systems, eds. Trauth, E., Howcroft, D., Butler, T., Fitzgerald, B., DeGross, J., (Boston: Springer), pp. 367-380. 
The idea of social exclusion has conceptual connections to discussions about poverty and capability deprivation (O'Brien et al. 1997; Sen 2000; Silver 1994). Historically the term social exclusion has been associated with economic disadvantage, where the lack of income has been regarded as a root-cause for inequalities among actors at different levels in the society. However, adopting a capability perspective on poverty implies a multidimensional perspective on the phenomenon, since actors value distinct capabilities differently (Sen 2000). Since the introduction of the term social exclusion more than 30 years ago, the meaning of the concept has expanded widely and is today an unclear, imprecise concept (O'Brien et al. 1997) congested with economic, social, political, and cultural connotations ( $O^{\prime}$ Reilly 2005). Social exclusion is, therefore, not only a result of lacking monetary capital, but can be attributed to lack of income over a wide range of different kinds of capital, including social, cultural, and symbolic capital. Acknowledging these aspects of social exclusion, this study is informed by Bourdieu and his idea of capital.

The term social exclusion has been interpreted in several ways (de Haan and Maxwell 1998). In this study we adopt the monopoly paradigm of social exclusion (Silver 1994), where social exclusion is seen as the consequence of group monopoly formation where certain groups are excluded from social closure. Within this paradigm, "the boundaries of exclusion may be drawn within or between nation-states, localities, firms or social groups" (Silver 1994, p. 543). Social exclusion is thus not only a phenomenon that operates at a societal level but also as a product of group dynamics in organizational settings. The focus on social exclusion in organizational groupings makes the characteristics of deprivation central in the analysis (de Haan 1998). Centralizing deprivation makes it possible to identify the criteria for inclusion and exclusion in organizational communities.

In this paper, we consider social inclusion and exclusion as related to communities of practice. It is generally accepted that communities of practice can be described as a group of people that share a basic interest or a passion for something (Lave and Wenger 1991; Wenger 1998). Communities of practice can be regarded as collectives with a high degree of shared capital. In one sense, gaining acceptance into the community means new members must to a large extent share the same capital as the other members of the community. Social inclusion and exclusion in terms of the community of practice is based on the degree to which people conform to the existing practice of that community. However, when these communities intersect within an organization, it raises the possibility of the social inclusion and exclusion of a community of practice as a whole. This might occur when the capital shared within the community has little importance or value among the other communities of practice within an organization. If a community's capital is undervalued outside of that community, all of its members may become excluded.

Using the notion of capital as a frame, we explore conflicts between social groups in a systems development organization. The research question we explore is: How does social exclusion affect software development organizations? We frame an interpretive analysis of the struggle of one professional group of developers to gain social inclusion within the remainder of the organization's software development communities. We show that software developers are not merely engaged in technical practice, but also in a social practice, in a constant struggle over scarce resources to position themselves in 
the organization to exert influence and consolidate their positions in the engagement of communities of practice.

\section{CASE DESCRIPTION AND METHODOLOGY}

This research engaged a company that may best be characterized as a software development organization specializing in mission critical applications over a wide range of business areas. The company (hereafter called Acme, a pseudonym) employs more than 300 people, most of whom hold academic degrees in systems engineering.

In the late 1990s, Acme settled on a strategic direction to concentrate focus on the capability maturity model paradigm (Humphrey 1989; Paulk et al. 1993) as a means to improve its systems development capabilities. Today Acme is certified level five according to the CMMI model (Chrissis et al. 2003). In its effort to implement the level five processes of the CMMI model, Acme has chosen to base the organizational implementation on the Microsoft Solution Framework (Microsoft 2003). Primarily, the team model presented in this framework has provided the inspiration for organizing Acme's knowledge network. Six disciplines are represented in the team model: Program Management, Development, Test, Release Management, User Experience, and Product Management.

Today each individual network is organized as something of an autonomous community of practice: a knowledge net consists of a number of members managed by a knowledge leadership group with typically four representatives. These representatives are considered to be professional experts within the discipline. The knowledge leadership is responsible for optimizing the process within the discipline and ensuring that state-of-the-art knowledge is continually evaluated and disseminated to the members of the network. The network also interacts with projects in the organization on a regular basis to ensure that this knowledge is applied in practice.

The decision to base the improvement effort on MSF was motivated by two factors. Apart from providing the organization with a framework for organizing the institutional tailoring of the high level processes of the CMMI model, this approach also addressed an emerging issue experienced in the projects: a lack of user involvement. Acme had recently been exposed to bad publicity regarding the user interfaces of its software products for a highly prestigious public project. This incident turned the attention to MSF, where the User Experience role is an integrated part of the framework. Top management agreed to adopt this framework, thus justifying the employment of people with skills in designing User Experience; a role that has not traditionally been represented in the systems development process. In this way, the justification for employing the User Experience people was motivated by an external demand for focus on the tangible design of the end product, not the internal architecture of the product that up to then had been a quality criteria in Acme.

The integration of technologies like CMMI and MSF into development practice produces increased perception of user and group empowerment (Adams et al. 2005). These models are in themselves loaded with certain values. In this study we acknowledge these technologies as structures that sustain the practice of the established community and thereby influence the criteria on which social exclusion and inclusion are determined (Adams et al. 2005). 


\subsection{Data Collection}

This research is empirically grounded in an ongoing action research project. For the past 2 years, we as researchers have had regular access to the organization and engaged in work activities to collect data. This study is most accurately categorized as a case study within an action research project (Germonprez and Mathiassen 2004), although the study relies heavily on a thorough understanding of how Acme operates as an organization acquired through joint collaboration on action taking.

The practical problem that drove forward the case study design was centered on the disparate performance of the networks in the organization assessed on the basis of a general survey among members of the knowledge networks. The survey demonstrated that the User Experience network achieved the absolute lowest score, whereas the Test network was ranked as the overall best functioning network.

The specific data collection for this study involved 10 interviews. Subjects included two members of each network, two representatives from each network's knowledge leadership, and the knowledge leader in each network. The four interviews with the knowledge leaders serve as the primary data source used for the analysis in this study because of their central position in the networks. Subsequently the results of the study were presented to the knowledge leaders in Acme in order to triangulate the findings and to give the interviewees an opportunity to comment on the conclusions.

The interviews were conducted using a semi-structured interview guide, with six major categories. The six categories were focused on the respondents personal work in the organization, the application of knowledge in their work, their role in the knowledge network, their personal evaluation of the knowledge network they represented, changes, and, finally, current challenges and problems. Each interview was scheduled for 1 hour and was recorded with the respondents knowledge and permission. To protect the anonymity of the interviewees, they will be referenced as knowledge leader one through four (KL1-KL4) in the analysis. The interviews were all recorded and subsequently transcribed.

\subsection{Interpretive Analysis}

Our goal is the understanding of deeply held social and cultural beliefs of a community, rather than those of individuals. We approached the analysis using an interpretive frame (Walsham 1995) that regarded the interview transcripts as a collective text. Any such text can be interpreted using techniques from literary analysis (Johnson 1980; Norris 1982). Such analytical techniques are not only applied in literature and poetry, but have also been applied in marketing and advertising (Ahuvia 1998) as well as in information systems (Beath and Orlikowski 1994; Truex et al. 2000). Our analysis not only includes consideration for the message intended by the author (authorial intent), but also for multiple meanings that arise from the text itself in the context of the communities of practice.

\section{ANALYTICAL FRAMEWORK}

In the analysis, our interpretation is inhabited by a purpose of explicating social inclusion and exclusion. This study applies the work of the French sociologist Pierre 
Bourdieu as an analytical framework to help guide the interpretation and help identify relevant passages in the empirical data. Bourdieu's theory is centered on three key elements that together seek to explain how social practice emerges. Bourdieu represents the logical relationships among the central concepts of his theory in an equation as $[($ Habitus $)($ Capital) $]+$ Field $=$ Practice $($ Bourdieu 1984, p. 101).

The field is defined as the social context in which social actors take part. The field is characterized by detached historical relations and structures anchored in certain forms of power or capital (Bourdieu and Wacquant 1992, p. 16). Within this arena, actors operate and fight for desirable resources. The field thus becomes a structured space of positions determined by the distribution of capital. Acceptance into a certain field can only be granted if the individual, who wants to enter, conforms to the governing social norms and displays an acceptable pattern of behavior (Kvasny 2002). Fields with a high degree of autonomy have high entry barriers for newcomers (Bourdieu and Wacquant 1992, p. 100), who must share the belief in the value of capital at stake in the field.

Habitus is defined as the existential setting that surrounds an actor. This includes internalized social norms and patterns of behavior. The habitus shapes the beliefs and character of individual actors. Habitus thus becomes the embodied practices that guide human agency. Bourdieu (1977) defines habitus as "a system of lasting, transportable dispositions which, integrating past experiences, functions at every moment as a matrix of perceptions, appreciations and actions and makes possible the achievements of infinitely diversified tasks."

Capital is a power resource that individuals can use to enter or change position in the field (Bourdieu and Wacquant 1992). Bourdieu defines four different kind of capital:

1. Economic: Monetary resources

2. Social: Group membership, relationships, networks of influence and support

3. Cultural: Knowledge, skills, competencies, education, and credentials

4. Symbol: Accumulated honor and prestige

The various forms of capital are means of power that can be used by actors to position themselves in the field. The relative importance of the various forms of capital is defined by the field.

\section{THE STUDY}

Our report below is structured according to the concepts in the theoretical framework. We attempt to expose the capital used by the interviewees in constructing the texts. Similarly, we explore the field that exists within the organization by exposing apparent structures that inhabit the interview texts. By revealing the field in the organization, we seek to understand the kinds of capital that are valued by actors in the field. To empirically ground the study, our interpretation of selected passages from the interviews will be presented in the analysis.

The analysis helps expose incoherence or contradiction in the social structures that inhabit the interview texts. Such incoherence or contradiction might explain the social inclusion or exclusion of various actors in the organization. Accordingly, this analysis 
is not intended to be a normative interpretation that evaluates conceptual schemas against a set of norms, but rather to more directly expose tensions and contradictions among the professional groupings in Acme. The aim is to identify naturally concealed aspects of practice in the software organization. In the following sections we seek to unveil the basic characteristics of the key elements central to Bourdieu's theory for actors in the two networks under investigation in Acme.

\subsection{Defining the Habitus}

It appears from the texts that the knowledge leaders in the User Experience group (KL1 and KL2) do not share common characteristics in their individual habitus. The two people come from different professional backgrounds and display different patterns of behavior. One of the knowledge leaders sees it as a prime objective to establish a well functioning network (words that provided key signs in the interpretation are underlined):

\section{We have an ambition in the network to also get the feeling that it is fellowship. but we do not feel this today, because the members do not make any con- tributions. (KL 1)}

The use of the term fellowship has very thick connections, relationships of strongly held, closely shared values. The marginalized text is that KL1 wants to avoid being shunned or excommunicated from this community, or perhaps to shun others. An ambition to establish a User Experience fellowship, of course, is structured by the shared desire ("we") for the fellowship, but the lack of contribution by members. This clear contradiction could mean that "we" is really structured by "I." The text suggests the lack of shared values that would drive contributions, and KL1 believes his values should drive a powerful fellowship. KL1 is very focused on the process view, since a lot of his work effort is put here. KL1 surprisingly marginalizes the end-user in the interviews by not mentioning this group at all, although it is a prominent task for a knowledge leader in a User Experience network.

KL2 on the other hand marginalizes the process view that is central to the organization given its strategic interest for the CMMI model. Top management in Acme has emphasized the importance of the process view in the charter for the knowledge network mechanism. Yet KL2 does not refer to the process work that might be the most important part of the work in knowledge leadership. However, KL2 is very focused on the demonstration of the value of User Experience in the actual projects in the organization that develop software products.

The only time that User Experience succeeds is when you are out in the projects and get things to happen. Events and posters where everybody can see us including processes are $O K$, but there's got to be some executive powers. (KL2)

In this passage, success is connected with getting things to happen (real work). Processes are connected to executive powers ("where everybody can see us"). The frame- 
work of the text shows how KL2 values real work in the projects and the process work is some showpiece for the executives, perhaps disconnected from actual productive work.

The habitus of the User Experience knowledge leaders is quite divergent, especially in terms of the value of processes. In the Test network, on the other hand, it is apparent that the habitus of the knowledge leaders to a large extent is consistent and that they share characteristics. The actors espouse the same values and have a view of the knowledge network that is consistent with the official knowledge network charter.

The most important thing, when you are part of the leadership in a network, is to be able to do leadership. That is, get the network to work! (KL3)

The process view is so strongly embodied in KL3 that the product view defers to this. Leadership gets the network to work. In the margins only do we find that it is the network that gets the product to work. In contrast to the User Experience network knowledge leaders, the Test network leaders see as their most prominent task to lead the network. There is no talk of fellowship or lack of contributions. The interview is constructed on the basis that members are actively involved in the work of the knowledge network, not in the construction of the knowledge network.

\section{I see the knowledge network as an educational institution. It is all about raising the knowledge level in house. (KL4)}

Underlying this passage is the unit of analysis (the house and not the network). The network and its benefits are organization-wide, not located within a single group. This value reveals how the habitus of the knowledge leaders in the Test network is oriented toward the field in the organization. The values used to construct interviews with the User Experience network were different. The knowledge leaders of the Test network seamlessly fit the characteristics of the organization whereas the knowledge leaders of the User Experience network have difficulty in establishing an identity both internally and externally.

\subsection{Valued Capital in the Field}

Competing values and behavior prevent the knowledge leaders in the User Experience group from defining a common ground. More importantly, the actors fail to establish themselves by not sharing the valued capital in the governing field in the organization. Moving our analysis to focus more specifically on these values, the analysis reveals the specific forms of capital at stake in the field.

\subsubsection{Social Capital}

The field in organizations is heavily influenced by the structures in the organization. The determined adoption of the CMMI framework has influenced the design of the organization and has become a structure that guides practice. The concept of process 
has in this way become an influential source of valuable social capital, because these structures act as the focal point of all communication in the organization.

It is a classic question when you get introduced to the company. You are asked if you like processes. Little by little people become aligned, in the sense that they smile when you mention the word process...It is almost a question of religion. (KL3)

For actors to position themselves in the organizational field, they must believe in and value the process view. The religion metaphor used by KL 3 contains the unspokenof anathema that would characterize critiques of the process view. Indeed, the excommunication or shunning suggested earlier by $\mathrm{KL} 1$ is present in this text. If people do not support the process idea, they are considered nonbelievers. It becomes a central part of the social capital in the field, an important entry barrier for admission into the field and the social group. The presence of this value is also reflected by the frequent reference in all interviews to various processes in the organization.

I design processes. Right now I work intensely to get the User Experience part integrated into the common process definition of the organization. (KL1)

It cannot be the responsibility of the leadership e.g. to design new processes. This can be delegated out as a separate task. (KL4)

Do I follow any process? That's a good question. Well, I'm a part of a team where we follow a certain course of actions when reporting. But the work products that I deliver are not especially process controlled. KL2)

It is worth noting that the process concept is viewed in different ways across the two networks. The User Experience network is a fairly new discipline introduced by the organizational adoption of the Microsoft Solution Framework. The processes for User Experience are not yet defined and deployed in the organization. Perhaps this is why they lack processes that define the requirement of User Experience work products. The User Experience work in the organization is therefore coordinated through the use of common management processes. The interpretation of the interviews reveals that if "it" doesn't have a process, "it" doesn't exist, since the process is a fundamental structure in the field and a touchstone for all other aspects in the organization.

There is a big difference in the conception of the relationship between a process and a network. Where the Test network sees themselves as detached from their process, the User Experience network sees themselves as an internal part of their process. There are fundamentally conflicting views on processes and how processes are understood and valued differently by the two groups.

\subsubsection{Cultural Capital}

The cultural capital of value in the field seems to be based on a set of principles often associated with those of engineers. These values are openly expressed in the 
organization because of the overwhelming presence of engineers in the organization. These values may make it difficult for people from other disciplines, unindoctrinated in these values, to influence the shape of the capital in the field. Rather, people with competing beliefs must become assimilated into the governing cultural capital of the field.

It is really disreputable when we [User Experience people] are in the project. It is really an environment where the technical foundation has a high weight. When you sit as a UE representative among 50 others and argue that it is not supposed to be like that; then they will answer: But that's the way it is! (KL2)

An unspoken concept inhabiting this passage is the source conflict KL2 has developed with others in the project. People don't explain to KL2 what is valued, they expect KL2 to understand (KL2 doesn't). User Experience people encounter the difficulty of penetrating the established ethos of the engineer. User Experience is a new discipline within systems development. KL2 earlier in the interview characterized this discipline as having a soft approach to systems development, safeguarding the interest of the end user based on a competing set of values. Such values contradict the principles of the engineer. KL3 characterizes the company as follows:

We are still an engineering company. This means that engineers to a great extend are very confident people who can work independently and who quickly can reach conclusions. (KL3)

\subsubsection{Symbolic Capital}

In terms of symbolic capital, the interviews clearly demonstrate that a practical demonstration of expertise can change an actor's position in the field.

It is still a struggle being an unbalanced entity. For example, the User Experience network, they steadily fight for their acceptance. It has been a tough battle. In fact, Test has been through the same. It has actually arrived while I have been here. You must damn well prove you are worthy, before you will get a place at the table. (KL3)

The value of practical demonstration of expertise is also revealed elsewhere in the analysis. All of the interviewees refer to previous or anticipated accomplishments in the organization, but there are unspoken differences between the User Experience group and the Test network. Both knowledge leaders in the Test network refer to accomplishments that are centered on processes. KL3 reports on an ongoing redesign of the existing process structure in the organization and KL4 concentrates on the development of an automatic unit test and GUI test to support the existing test process. Both actors are constructing the interviews in the context of anticipated savings in monetary capital that is particularly important in the field: cost reduction and time.

No such pattern seems to have been present in the construction of the interviews with the User Experience network. Nowhere do KL1 and KL2 refer to accomplishments that might be measured in any particular capital at all. 


\subsection{Defining the Field}

During the process of analyzing the interview texts, certain themes emerged that prove valuable for achieving a deeper understanding of social exclusion in the software development process. In this section we will draw on selected parts of the texts to highlight these themes.

Organizational inclusion is of great importance for the User Experience people. This is not an issue in the Test network; they take it for granted that they are socially included in the organization. Recall KL3's earlier comment, "You must damn well prove you are worthy, before you will get a place at the table. By pointing out how the Test network has been through similar circumstances, KL3 marginalizes the issue of acceptance as an issue that is of importance to the Test network today; inclusion is taken for granted. Also the event or basis for the acceptance has been marginalized. It is not revealed how the Test network made the transition from being socially excluded to being included in the organization. This tacit achievement is left obscure and secret. Thirdly, the choice of the metaphor "get a place at the table" implies a transition phase from being invisible to becoming visible in the organization. The text is constructed with the idea of a test where you get the opportunity to prove the value of your competencies. Finally the struggle is characterized as a steady fight, a tough battle. KL1, independent of KL3, makes use of the same battle metaphor to describe the current situation for the User Experience network.

\subsection{The Battle Metaphor}

For the last two years my main focus has been on the design of user interfaces. The User Experience network did not exist at this point in time. I fought a lonely battle for more than ten months before the MSF roles were formally introduced. (KL1)

... because a project can tailor its own process more or less as it pleases and because project managers possess a lot of power, then it doesn't by design ensure that User Experience will become a part of the project process.... when a project manager is pressed for time they will drop processes that they do not know a lot about or processes that they believe will generate less value. It is an ongoing battle. (KL1)

These two extracts illustrate the context in which KL1 uses the battle metaphor. The interviewees repeatedly make reference to this combat metaphor. The texts show how KL1 sees himself as a champion; one that, given the singularity in values shown in the interpretation that revealed his habitus, perhaps has undertaken a heroic quest as a lonely champion. KLl seeks to fight for the values in which he believes and that are not shared by other individuals in the organization. In the detailed accounting of the quest, KLl never explicitly mentions the enemy that needs to be fought. The interpre-

'In Danish literally, "on the wall." 
tation of this text reveals a champion with a cause but no clearly defined monster to battle. This is marginalized, a part of the story that was present for the interviews, but missing from the interview text itself.

\section{I have simply got a sound beating and I was really low in the established hierarchy. (KL1)}

The text makes reference to the "sound beating" of the champion. Yet, the monster that beat $\mathrm{KLI}$ is marginalized. KLl never names the monster that must be defeated to gain wide-spread acceptance in the organization. But the monster inhabits both networks. KL2 also fights this battle.

The purpose of User Experience network is to get more attention in house. There are two objectives: one is directed inwards, that is, we become better at what we are doing, and the second is directed outwards: that is, to render the User Experience part of the systems development visible to the organization. (KL2)

By emphasizing the importance of getting attention in house and rendering the User Experience network visible in the organization, KL2 marginalizes how the network is not visible in the house today. To become visible, the User Experience network must prove that they are worthy of their place at the table. Yet the battle that KL2 fights is not valued by peers.

This is still a discipline where we walk around-and I'm not the one to complain, because this is how it is in all organizations-and get into a context where there will be a natural resistance against what you represent. It corresponds to the job of internal police. (KL2)

KL2 uses the label "internal police" to characterize his own responsibility in the process. Internal police serves as a control function to verify that some unpronounced "law" is enforced. Present in this passage is a certain legalistic code that requires force to enact. This comparison indicates that KL2 is aware of the resistance among his peers for what he represents and the (unspoken) violence necessary to overcome it.

Common in the underlying premises of KL1 and KL2 is that neither has earned the right to be in the field. The monster that they are struggling to subdue is not necessarily the same monster recognized and valued in the field. The User Experience network may have indeed failed to demonstrate to the field that this is a worthy monster to subdue and that its conquest should earn the capital that would penetrate the barriers for newcomers to the field. To penetrate the entry barriers of the field, the User Experience monster must be great enough to gain professional acceptance among peers in the organization. At this point in time, the User Experience network seems to be socially excluded because they haven't earned the capital that comes from battling and vanquishing a significant monster that roams the field. 


\section{DISCUSSION AND CONCLUSION}

The use of Bourdieu's theory of social practice as an analytical lens to understand the mechanisms of social exclusion has contributed new insight into how professional communities new to an organization must struggle for social inclusion among peers. We have highlighted the metaphors of monsters, champions, battles, and conquests because these enliven our descriptions of the interview texts and the interpretive analysis. Indeed these metaphors were present in the interview text, although unpronounced by the actors. The underlying mechanics of social exclusion described in these texts can be explained in general terms as follow.

Larger software development organizations provide a venue for the intersection of a variety of communities of practice. This intersection provides a social engagement that constitutes a field. In software development organizations, newcomers to such a cohesive social group of peers with distinct shared values (i.e., a field or a community of practice) will be excluded until they demonstrate socially acceptable behavior and accumulate the right kinds of capital as defined by the larger field. For the particular case of this software development firm, this admission is dependent on a threshold event. This threshold event wins social inclusion for the excluded group, in this case, one community of practice.

The threshold event for this organization appears to be the acquisition of ownership of a respectable process by the individuals awaiting admission. This threshold event is a struggle, akin to vanquishing some monster. But the quality of the monster is an issue. The field collectively decides whether the monster is of sufficient magnitude to warrant the capital needed to enter. In our case, the software development organization socially decides whether the User Experience group has gained sufficient ownership of a sufficiently respectable process to be socially included.

There are some very important social features in the case concerning this threshold event. First, there is no formally pronounced process of social inclusion or exclusion in the organization. The User Experience network is by definition part of the formal organization. But everyone, including the User Experience network members, understands very precisely that they are outsiders, socially excluded from the rest of the network because they have earned no capital in the social field within the formal organization.

Second, no one ever tells newcomers that there is a threshold event or that they must find it and complete it, and what makes the event valuable. It is an unspoken assumption, understood and shared by all of the actors in the field. It's sort of, " $W e$ 'll know it when we see it." Even this vagary is never pronounced, but simply inhabits the social texts. Newcomers are socially excluded from the community of practice until the threshold event occurs. Discovery that such an event brings the capital necessary to win admittance to the field is all the more difficult when a complete community of practice has been excluded. Newcomers may be doing the "right things" from the viewpoint of their peers within their own community of practice, yet doing the "wrong things" from the viewpoint of the peers within a larger field.

Third, loss of valued capital can lead to loss of position in the field. A group can lose its social inclusion by not keeping up skills, know-how, and command over their process. In other words, groups that are not vigilant will degenerate and be excluded. In other words, new monsters grow and attack the careless. 
How, then, does social exclusion affect software development organizations? We have demonstrated that within organizations or between certain communities of practice, despite implementations of formal structures to the contrary, newcomers may be socially excluded. Efficiency and effectiveness in the software development process may consequently be limited because the integration of some functions in practice is not recognized by peers. In our case, the professional community in User Experience is socially excluded from the larger field because peers do not recognize the qualifications held by these people. In practice, this means that the User Experience community fails to safeguard the interest of the end user- not because there is a lack of formal structures or management commitment, but because the User Experience people haven't accumulated the right kind of capital to enter the larger field and become socially included.

For some software development organizations and communities of practice, winning social inclusion involves a threshold event that is recognized by the actors in the field as winning sufficient capital to gain position in the field. The existence and nature of the threshold event may never be expressed, although it inhabits the social constructs of the organization with great strength. In one sense, the threshold event is something of a monster that must be discovered and vanquished by the newcomers, within the unspoken recognition and approbation of the other organizational or community of practice members. Only champions grow worthy of social inclusion.

\section{References}

Adams, A., Blandford, A., and Lunt, P. "Social Empowerment and Exclusion: A case Study on Digital Libraries," ACM Transactions on Computer-Human Interaction (12:2), 2005, pp. 174-200.

Ahuvia, A. C. "Social Criticism of Advertising: On the Role of Literary Theory and the Use of Data," Journal of Advertising (27:1), 1998, pp. 143-162

Beath, C. M., and Orlikowski, W. J. "The Contradictory Structure of Systems Development Methodologies: Deconstruction the IS-User Relationship in Information Engineering," Information Systems Research (5:4), 1994, pp. 350-377.

Bourdieu, P. Distinction: A Social Critique of the Judgement of Taste, Cambridge, MA: Harvard University Press, 1984.

Bourdieu, P. Outline of a Theory of Practice, Cambridge, UK: Cambridge University Press, 1977.

Bourdieu, P., and Wacquant, L. J. D. An Invitation to Reflexive Sociology, Chicago: The University of Chicago Press, 1992.

Chrissis, M. B., Konrad, M., and Shrum, S. CMMI: Guidelines for Process Integration and Product Improvement," Boston: Addison Wesley, 2003.

de Haan, A. "Social Exclusion: An Alternative Concept for the Study of Deprivation," IDS Bulletin (29:1), 1998, pp. 10-19.

de Haan, A., and Maxwell, S. "Poverty and Social Exclusion in North and South," IDS Bulletin (29:1), 1998.

Germonprez, M., and Mathiassen, L. "The Role of Conventional Research Methods in Information Systems Action Research" in Information Systems Research: Relevant Theory and Informed Practice, B. Kaplan, D. Truex, D. Wastell, A. T. Wood-Harper, and J. I. DeGross (eds.), Boston: Kluwer Academic Publishing, 2004, pp. 335-352.

Humphrey, W. Managing the Software Process, Reading, MA: Addison-Wesley Publishing Company, 1989. 
Johnson, B. Critical Difference: Essays in the Contemporary Rhetoric of Reading, Baltimore, MD: Johns Hopkins University Press, 1980.

Kvasny, L. Problematizing the Digital Divide: Cultural and Social Reproduction in a Community Technology Initiative, unpublished doctoral dissertation, Georgia State University, Atlanta, GA, 2002.

Lave, J., and Wenger, E. Situated Learning: Legitimate Peripheral Participation, Cambridge, UK: Cambridge University Press, 1991.

Microsoft. Microsoft Solution Framework v3.0 Overview, Microsoft Corporation, Redmond, WA, 2003.

Norris, C. (1982). "Deconstruction - Theory and Practice," London, Routledge.

O'Brien, D., Wilkes, J., de Haan, A., and Maxwell, S. "Poverty and Social Exclusion in North and South," Institute of Development Studies and Poverty Research Unit, University of Sussex, 1997.

O'Reilly, D. "Social Inclusion: A Philosophical Anthropology," Politics (25:2), 2005, pp. 80-88.

Paulk, M. C., Curtis, B., Chrissis, M. B., and Weber, C. "Capability Maturity Model for Software ver. 1.1," Technical Report CMU/SEI-93-TR-24, Software Engineering Institute, Carnegie Mellon University, Pittsburgh, PA, 1993.

Sen, A. "Social Exclusion: Concept, Application, and Scrutiny," Report to the Office of Environment and Social Development, Asian Development Bank, Manila, The Philippines, 2000 .

Silver, H. "Social Exclusion and Social Solidarity: Three Paradigms," International Labour Review (133:5/6), 1994, pp. 531-578.

Truex, D., Baskerville, R., and Travis, J. "Amethodical Systems Development: The Deferred Meaning of Systems Development Methods," Accounting Management and Information Technologies (10:1), 2000, pp. 53-79.

Walsham, G. "Interpretive Case Studies in IS Research: Nature and Method," European Journal of Information Systems (4:1), 1995, pp. 74-81.

Wenger, E. Communities of Practice: Learning, Meaning, and Identity, Cambridge, UK: Cambridge University Press, 1998.

\section{About the Authors}

Richard L. Baskerville is professor and chairman of the CIS Department at Georgia State University. His research and authored works regard security of information systems, methods of information systems design and development, and the interaction of information systems and organizations. Richard is the author of Designing Information Systems Security (John Wiley \& Sons) and more than 100 articles in scholarly journals, practitioner magazines, and edited books. $\mathrm{He}$ is an editor for The European Journal of Information Systems, and associated with the editorial boards of The Information Systems Journal and The Journal of Database Management. $\mathrm{He}$ is a Chartered Engineer, holds a B.S. summa cum laude from The University of Maryland, and the M.Sc. and Ph.D. degrees from The London School of Economics. Richard can be reached at baskerville@acm.org.

Thomas Elisberg is a Ph.D. student at the IT University of Copenhagen. His primary research interests regard information systems development and software process improvement focusing on organizational and managerial issues. He holds an M.Sc. in Computer Science and Business Administration from Copenhagen Business School. Thomas can be reached at elisberg@itu.dk. 